\title{
Bone scintigraphy in the management of X-ray-negative potential scaphoid fractures
}

\author{
A. W. WILSON ${ }^{1}$, M. H. J. KURER ${ }^{2}$, J. L. PEGGINGTON ${ }^{2}$, D. S. \\ GRANT $^{2}$ AND C. C. J. KIRK ${ }^{1}$
}

${ }^{1}$ The London Hospital, Whitechapel, and ${ }^{2}$ University College Hospital, London, England

\section{SUMMARY}

One hundred and eleven patients with signs and symptoms of carpal scaphoid injury, but with no fracture visible on X-ray, underwent bone scintigraphy of the wrists. The first 42 patients were re-X-rayed 10 days after injury: bone scanning had identified all fractures confirmed on this X-ray; there were no false negative bone scans.

Sixty-seven patients $(60 \%)$ did not have increased focal uptake over the scaphoid or distal radius, and were mobilised immediately. None of these had a fracture at follow up. Twenty-nine patients with increased uptake over the scaphoid area (26\%) remained in plaster of Paris for 6 weeks. All of these had clinical signs of a scaphoid injury.

Bone scanning is a practical investigation for all $\mathrm{X}$-ray-negative potential scaphoid injuries, and is acceptable to patient and clinician. In the presence of a normal scan, the practice of re-X-raying patients 10 days after injury may be abandoned.

\section{INTRODUCTION}

Fractures of the scaphoid are the most common carpal injuries. (Dunn, 1972; Southcott \& Rosman, 1977). Radiographs obtained shortly after trauma may not reveal the fracture (Mack et al., 1984; Leslie \& Dickinson, 1981). Early recognition and immobilization is important to avoid pseudoarthrosis at the fracture site or avascular necrosis of the proximal fragment. To avoid these sequelae, it is accepted that, where there is anatomical snuff-box tenderness after trauma to the wrist, the wrist should be immobilised in plaster of Paris for 10 days. The plaster is then removed and the wrist examined and re-X-rayed. Only if there is neither clinical nor radiological evidence of scaphoid injury is the wrist then mobilised. Inevitably, many patients are immobilized unnecessarily. 
Several authors have shown that bone scintigraphy (BS) is a valuable supplementary $\frac{\mathbb{\Phi}}{0}$ examination in the assessment of bone trauma. (Fordham \& Ramachandran, 1979; 3 Batillas et al., 1981; Rosenthal et al., 1976; Marty et al., 1976). In particular, there have $\stackrel{\mathbb{Q}}{\circ}$ been many reports of the usefulness of BS in the management of fractures of the $\overrightarrow{\vec{F}}$ scaphoid (O'Carroll et al., 1982; Stordahl et al., 1984; Rolfe et al., 1981; Nielson et al., $\stackrel{\text { }}{\frac{1}{8}}$ 1983; Ganel et al., 1979).

Matin (1979) showed that $95 \%$ of all scaphoid fractures were visible on BS 72 hours $\frac{\frac{\sigma}{\bar{N}}}{\overline{6}}$ after injury, irrespective of X-ray appearances. This study was not primarily to assess $\stackrel{\mathbb{\Omega}}{\varrho}$ the accuracy but the practicality of scanning all X-ray-negative potential scaphoid fractures in a busy accident unit. We also compared scanning with X-ray results in a $\vec{\circ}$ smaller group of patients and evaluated the role of BS in preventing unnecessary immobilization.

\section{METHOD}

Seventy-three men and 38 women (mean age of 36 years) presented to the Accident $\mathrm{O}$ Unit with a history of trauma to the wrist. All had tenderness in the anatomical snuff box. No fractures were seen on routine antero-posterior, lateral and oblique X-rays of $\nabla_{\mathbb{D}}$ the wrist (Russe, 1960). Pain on telescoping the ipsilateral first metacarpal was assessed $\Phi$ in 68 patients. All patients were immobilised in plaster from below the elbow to the $\frac{7}{0}$ interphalangeal joint of the thumb. BS was performed within the first 10 days of $\stackrel{\mathbb{D}}{-}$ presentation in most cases, avoiding the first 24 hours. Potentially pregnant womeg were excluded. Three hours after an intravenous injection of $500 \mathrm{MBq}$ of $9 \mathrm{~m}$ Technet. tium-labelled methyl-diphosphonate, the patients were scanned with a 37 tube Gammi camera. Both wrists were placed together on the camera face to maximize resolution. The uninjured wrist acted as the normal anatomical control for each individual and also as an indicator of bilateral pre-existing bone disease. The plaster was not removed, and as lateral views did not contribute to interpretation, only palmer views were performed.

The whole body radiation count for BS is 1 milligray and 0.04 milligrays for a chest $\mathrm{X}$-ray. The bone marrow dosage for chest $\mathrm{X}$-ray is 0.03 milligrays and 4.0 milligrays for BS. Bone scans were interpreted according to previously defined criteria (Sy et al., 1977). Abnormal scans were diagnosed when asymmetry between hands or between a $\stackrel{\mathbb{D}}{\exists}$ focal area and adjacent bones occurred. If abnormal focal uptake was found, it was related to the corresponding carpal bone. The scaphoid was localized on the bone scan by constructing lines between the midpoint of the distal radial articular surface and the junction of the second and third metacarpal bases, and between the ulnar styloid and the base of the first metacarpal (see Fig. 1).

The first 42 patients in the series also had follow up X-rays at 10 days.

The scans were reported by a clinical anatomist with a special interest in this area and an accident unit surgeon jointly. The X-rays were reported by one radiologist. All patients with increased focal uptake over the scaphoid or distal radius remained in plaster and were referred to the fracture clinic. Patients without focal uptake over the scaphoid or radius were taken out of plaster and mobilised. Those with increased generalised uptake were treated as sprains and given double Tubigrip bandaging and referred for physiotherapy. Other bone injury was treated appropriately. 


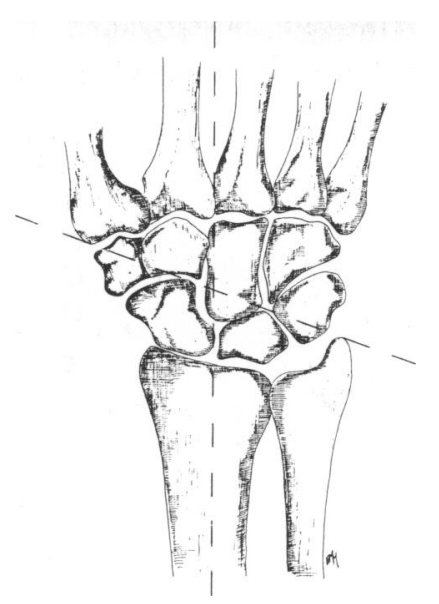

Fig. 1 Localization of the scaphoid.

\section{RESULTS}

One hundred and eleven patients with initially normal scaphoid X-rays were scanned. Twenty-nine of these $(26 \%)$ had increased uptake consistent with scaphoid fracture. Other wrist injuries were seen in 65 patients $(60 \%)$. Nineteen patients $(17 \%)$ also had injuries to one or more other carpal bones. Five patients $(4.5 \%)$ had areas of increased uptake consistent with arthritis but this did not hamper interpretation. Generalised increased uptake was seen in 62 patients and was seen with equal frequency from 1 to 60 days after injury. Table 1 lists sites of injuries seen on BS.

On the contralateral hand, injuries to the distal radius, first, third and fourth metacarpals, triquetral, and lunate were seen. In 11 patients $(10 \%)$, increased generalised uptake alone was found. Only 5 patients $(4 \cdot 5 \%)$ had completely normal scans.

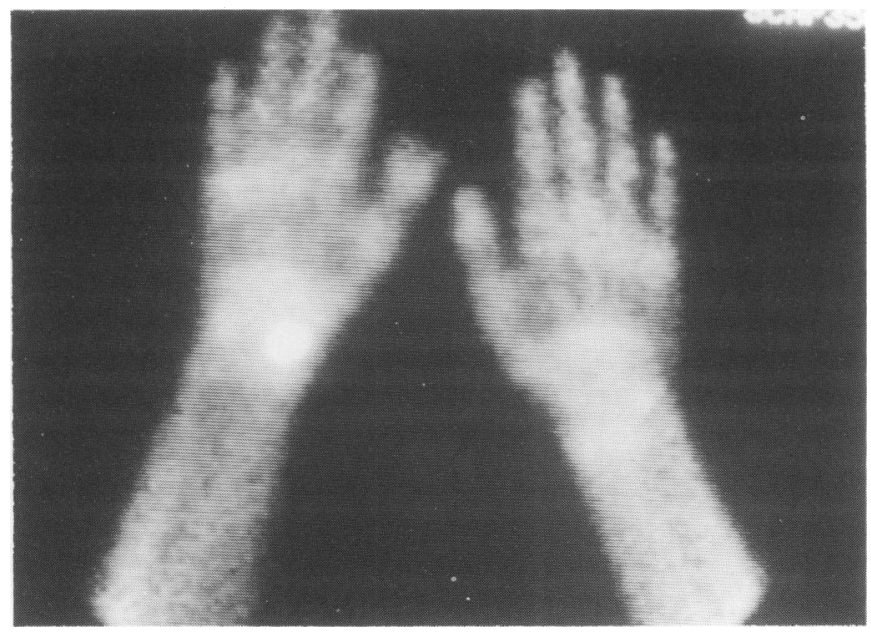

Fig. 2 Bone scan showing increased uptake over the left scaphoid. 
Table 1 Sites of injuries

\begin{tabular}{lcc}
\hline Injury site & No. & $(\%)$ \\
\hline & & \\
Scaphoid & 29 & $(26)$ \\
Distal radius & 13 & $(12)$ \\
Trapezium & 12 & $(11)$ \\
First metacarpal & 11 & $(10)$ \\
Triquetral & 9 & $(8)$ \\
Capitate & 7 & $(6)$ \\
Lunate & 6 & $(5)$ \\
Ulnar styloid & 2 & $(2)$ \\
Hamate & 2 & $(2)$ \\
Fifth metacarpal & 2 & $(2)$ \\
Fourth metacarpal & 1 & $(1)$ \\
Second metacarpal & 1 & $(1)$ \\
\hline
\end{tabular}

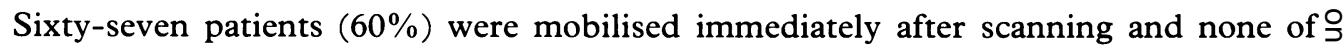
these was subsequently shown to have a fracture.

The first $\mathbf{4 2}$ patients received follow up X-rays at 10 days. In only two of these was a confident diagnosis of scaphoid fracture made. Both were confirmed on BS. Radiological signs, consistent with but not diagnostic of a fracture, were reported in seven cases. None of these had abnormal scaphoid scans and none went on to become X-ray positive, The remaining 33 patients were reported as normal on the 10-day X-ray but six of them had increased uptake over the scaphoid on BS. This was in agreement with the finding of other investigators (O'Carroll et al., 1982; Stordahl et al., 1984; Rolfe et al., 198 Nielson et al., 1983; Ganel et al., 1979).

The results of the assessment of the metacarpal telescoping sign in 68 patients are shown in Table 2.

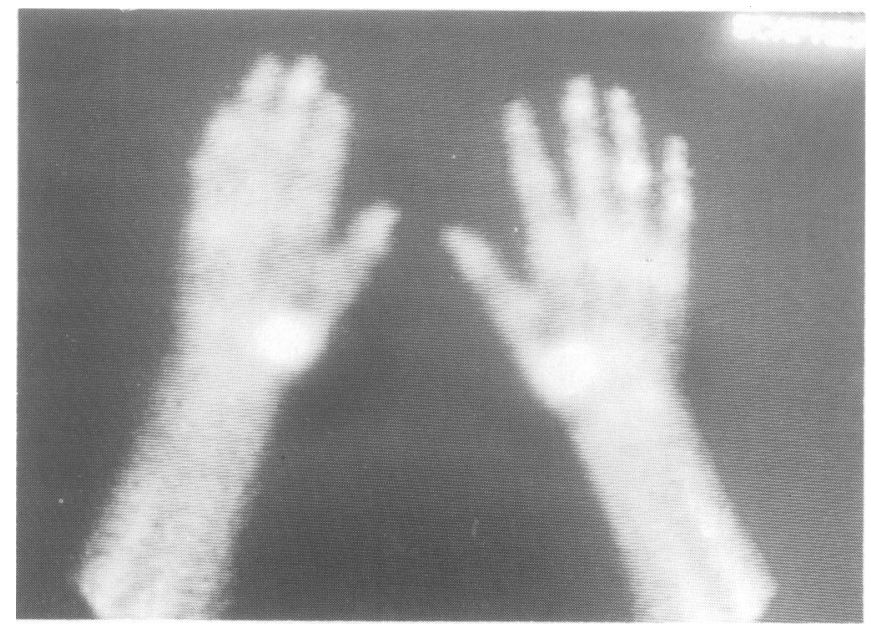

Fig. 3 Bone scan showing bilateral increased uptake over both trapeziums. 
Table 2 Increased uptake

\begin{tabular}{lccccc}
\hline & \multicolumn{2}{l}{ Positive telescoping sign } & & \multicolumn{2}{l}{ Negative telescoping sign } \\
\cline { 2 - 3 } \cline { 5 - 6 } & No. & $(\%)$ & & No. & $(\%)$ \\
\hline Fractured scaphoid & 9 & $(24)$ & & 7 & $(23)$ \\
Fractured first metacarpal & 4 & $(11)$ & & 3 & $(9)$ \\
Other fracture & 15 & $(41)$ & & 14 & $(45)$ \\
No boney injury & 9 & $(24)$ & & 7 & $(23)$ \\
Total & 37 & $(100)$ & & 31 & $(100)$ \\
\hline
\end{tabular}

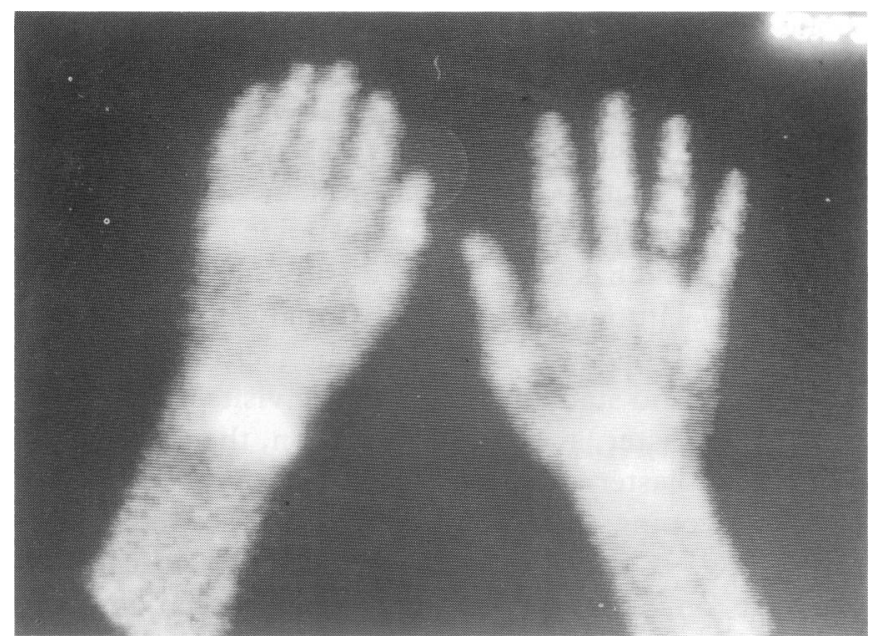

Fig. 4 Bone scan showing increased uptake over the left distal radius.

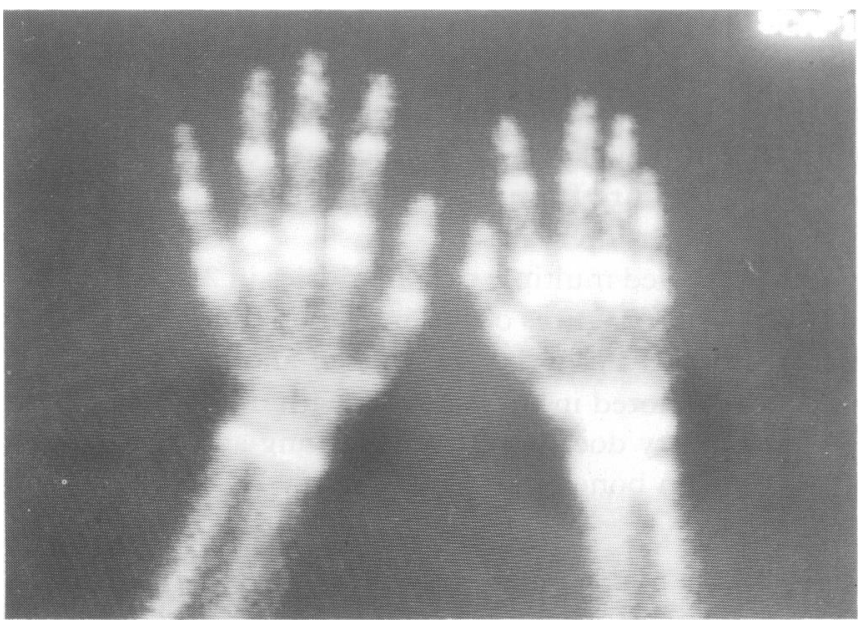

Fig. 5 Bone scan showing normal activity over unfused epiphyses, but increased uptake over the right distal radial epiphysis and right scaphoid. 
One hundred and eleven patients with X-ray-negative potential scaphoid injuries were scanned. Scanning was avoided within 24 hours of the injury because of reports that acute generalised uptake may mask a fracture (Matin, 1979). No difficulty was found in interpreting the scans after the first day, though generalised uptake was present up to 60 응 days after injury, suggesting prolonged hyperaemia presumably relating to the magni- $\frac{\overline{\bar{n}}}{\overline{\mathrm{n}}}$ tude of the injury. Sixty-seven patients $(60 \%)$ were safely mobilized on the same day as $\widehat{\Omega}_{\Omega}$ the scan and were saved unnecessary immobilization and the potential prospect of prolonged physiotherapy.

We confirm the accuracy of a negative bone scane as a screening tool. In the presence of a negative bone scan, the clinician may confidently mobilize the patient despite $\bar{\sigma}$ prolonged snuff-box tenderness. All such patients were reviewed by clinical examina-㪲 tion between 1 and 3 weeks and, in each case, the tenderness has resolved completely Those patients who remained in plaster for 6 weeks avoided plaster removal at 10 days. $A$ The inevitable wrist manipulation during physical and X-ray examination is an action which may, in itself, contribute to scaphoid non-union. This is avoided.

The cost of bone scanning has been assessed and found to be as much as four times that of X-rays (Bretland), although a less detailed analysis in our own department found the cost to be much less. This cost is offset by the fact that bone scanning avoids the inconvenience, to patient and staff alike, of multiple visits involving an initial examina- $\frac{3}{0}$ tion, the removal of the plaster, a repeat examination, then a repeat X-ray followed by the application of a new plaster and a plaster check the following day.

The metacarpal telescoping sign is not specific for scaphoid injury, and has be n. shown to be misleading. It should be discontinued. In no case where there was $\mathrm{J}^{2} \mathrm{o}$ suspicion of a fracture' on X-ray was a scaphoid injury seen on bone scan. Unless the radiologist can be certain of a fracture, the $\mathrm{X}$-ray may be misleading.

Unlike the clinical and radiological signs, scaphoid injuries are simpler to diagnose on bone scan. Unfortunately, false positives may occur. Increased focal uptake may be $\overrightarrow{\vec{F}}$ caused not only by a fracture but also by what are presumed to be subperiosteal 3 haematomata or ligamentous tears. There is no in vivo method of distinguishing between them. There is also an incidence of scaphoid non-union despite proper immobilization, and so it seems wholly justified in treating any focal increased uptake $\frac{\mathbb{\Phi}}{3}$ over the scaphoid as a fracture from the outset. Such patients should be X-rayed at 60 weeks rather than at 10 -day intervals.

Bone scintigraphy revealed multiple carpal injuries in 21 cases. This is contrary to theo popular notion that simple fractures occur only at one site. It is, therefore, important to search for occult fractures even in the presence of another obvious carpal bone injury..

Scaphoid injuries were noted in three people with unfused epiphyses. This confirms other reports that the injury does occur in the young and that separate specific foci of uptake are easily visible on bone scan (Green et al., 1984; Onuba \& Ireland, 1983).

\section{CONCLUSION}

Bone scintigraphy is a practical investigation for the management of $\mathrm{X}$-ray-negative 
potential scaphoid injuries. It is more sensitive than $\mathrm{X}$-ray, without false negative results and, in cases of scaphoid injury, is more acceptable to patient and clinician alike, as repeated plaster removal and repeated hospital attendance are avoided. Patients with normal scaphoid scans and trivial injuries avoid unnecessary immobilization.

Bone scintigraphy may, therefore, replace traditional 10-day X-rays.

The metacarpal telescoping sign is misleading and should be abandoned.

\section{ACKNOWLEDGEMENTS}

The authors would like to acknowledge the kind assistance of S. Huggett and E. Marcus in this study.

\section{REFERENCES}

Batillas J., Varilas A., Pizz W. F. \& Gockebuy T. (1981) Bone scanning in the detection of occult fractures. fournal of Trauma 21, 564-9.

Bedford, Glasgow M. M. \& Wilson J. N. (1981) Ultrasonic assessment of fractures and its use in the diagnosis of scaphoid fracture. Injury 14, 180-2.

Bretland A. MSc Thesis: personal communication.

Dunn A. W. (1972) Fractures and dislocations of the carpus. Surgical Clinics of North America 52, $1513-38$.

Fordham W. E. \& Ramachandran P. C. (1979) Radionuclide imaging of osseous trauma. Seminars in Nuclear Medicine 4, 411-29.

Ganel A., Ganel J., Oster Z. \& Farine I. (1979) Bone scanning in the assessment of fractures of the scaphoid. fournal of Hand Surgery 4, 540-3.

Green M. H., Hadied A. M. \& La Mont R. L. (1984) Scaphoid fractures in children. Fournal of Hand Surgery 9A, 536-41.

Herness D. \& Passner A. (1977) Some aspects of bone grafting for non-union of the carpal navicular. Acta orthopaedica Scandinavica 48, 373-8.

Kondogannis P. N. (1982) A clinical sign in suspected fractures of the carpal scaphoid. Fournal of Bone and foint Surgery 64A, 5.

Leslie I. J. \& Dickinson R. A. (1981) The fractured carpal schaphoid. fournal of Bone and foint Surgery 63B, 225-30.

Mack R., Bosse J., Gelbennan R. H. \& Yu E. (1984) The natural history of scaphoid non-union. Fournal of Bone and foint Surgery 66A, 504-9.

Marty R., Denney J. D. \& Mckaney M. R. (1976) Bone trauma and related benign disease: assessment by bone scanning. Seminars in Nuclear Medicine 6, 107-20.

Matin P. (1979) The appearance of bone scans following fractures including immediated and long-term studies. Fournal of Nuclear Medicine 20, 1227-31.

Nielson P. T., Hedeboe J. \& Thommesen P. (1983) Bone scintigraphy in the evaluation of fractures of the carpal scaphoid bone. Acta orthopaedica Scandinavia 59, 303-6.

O'Carroll P. F., Doyle J. \& Duffy G. (1982) Radiography and scintigraphy in the diagnosis of carpal scaphoid injuries. Irish fournal of Medical Science 151, 211-3.

Onuba O. \& Ireland J. (1983) Two cases of non-union of fractures of the scaphoid in children. Injury 15, 10912.

Rolfe E. B., Garvie N. W., Khan M. A. \& Ackery D. M. (1981) Isotope bone imaging in suspected scaphoid trauma. British fournal of Radiology 54, 762-7.

Rosenthal L., Hill R. O. \& Chuang S. (1976) Observation on the use of 99MTc-phosphate imaging in peripheral bone trauma. Radiology 119, 637-41.

Russe O. (1960) Fracture of the carpal navicular. Fournal of Bone and foint Surgery 42A, 768-99. 
242 A. W. Wilson et al.

Southcott R. \& Rosman M. A. (1977) Non-union of carpal scaphoid fractures in children. Fournal of Bone and쯩 foint Surgery 59B, 203.

Stordahl A., Schjoth A., Woxholt G. \& Fjermeros H. (1984) Bone scanning of fractures of the scaphoid. fournal of Hand Surgery 9, 189-90.

Sy W. M., Bay R. \& Camera A. (1977) Hand images normal and abnormal. fournal of Nuclear Medicine 18, 419-24.

Received 6 December 1985; accepted 25 May 1986 